\title{
The Effect of Multiwalled Carbon Nanotubes on Hepatotoxicity of $\mathrm{Cd}^{2+}$ in Accumulated Cadmium-Metallothione in Mice
}

\author{
Qi Wei, ${ }^{1}$ Bi Juanjuan, ${ }^{1}$ Tian Longlong, ${ }^{1}$ Li Zhan, ${ }^{2}$ Liu Peng, ${ }^{1}$ and Wu Wangsuo ${ }^{1}$ \\ ${ }^{1}$ Radiochemical Laboratory, Lanzhou University, Lanzhou 730000, China \\ ${ }^{2}$ Lanzhou Institute of Chemistry Physics, Chinese Academy of Science, Lanzhou 730000, China
}

Correspondence should be addressed to Wu Wangsuo; wuws@lzu.edu.cn

Received 21 May 2014; Revised 24 July 2014; Accepted 25 July 2014; Published 2 September 2014

Academic Editor: Lisa A. Delouise

Copyright (C) 2014 Qi Wei et al. This is an open access article distributed under the Creative Commons Attribution License, which permits unrestricted use, distribution, and reproduction in any medium, provided the original work is properly cited.

\begin{abstract}
The effects of oxidized multiwalled carbon nanotubes (oMWCNTs) on the behavior and hepatotoxicity of $\mathrm{Cd}^{2+}$ in accumulated cadmium-metallothionein mice were investigated. The results indicated that, after exposure of oMWCNTs to normal mice, oMWCNTs could not induce the liver to produce metallothionein (MT). When exposing Cd-MT mouse to different doses of oMWCNTs oMWCNTs could cause $\mathrm{Cd}^{2+}$ release from the accumulated Cd-MT; subsequently, one part of the free $\mathrm{Cd}^{2+}$ was eliminated with blood circulation; the other part adsorbed by oMWCNTs would remain in the tissues together with oMWCNTs. The results of the activities changes of alanine aminotransferase (ALT), aspartate aminotransferase (AST), total bilirubin (TB), and blood urea nitrogen (BUN) in plasma showed that the hepatotoxicity of coexposure was lower than that of single exposure, and the hepatotoxicity and accumulation of oMWCNTs in livers depended strongly on the exposure dosage of oMWCNTs. The histology of liver and kidney tissue also confirmed the previous results. Therefore, the author inferred that MT could be connected with oMWCNTs to reduce their hepatotoxicity, but the detailed mechanism needs to be further studied.
\end{abstract}

\section{Introduction}

Cadmium (Cd) is an environmental and industrial pollutant that poses a serious health risk to humans and animals. $\mathrm{Cd}^{2+}$ has multiple cytotoxic and metabolic effects, such as interfering with the normal actions of essential metals [1], including oxidative stress and altering the activities of various enzymes [2-4]. When $\mathrm{Cd}$ is exposed to animals, $\mathrm{Cd}$ is distributed mainly to the liver and kidney and accumulated with metallothionein (MT). MT is a small metal-binding protein that is characterized by its high thiol content; 20 of its 61 amino acids are cysteine, all of which are in the reduced state and are involved in its metal-binding properties. At the same time, it was also reported that there were two major isoforms of MT in mammals, designated MT-I and MT-II, which were coordinately regulated in the mouse and the proteins were thought to be functionally equivalent. MT can sequester $\mathrm{Cd}^{2+}$ from molecular targets by binding to $\mathrm{Cd}^{2+}$ with high affinity and, thus, making it less available for excretion; some researches indicate that MT appears to accumulate $\mathrm{Cd}$ in a less toxic form until reaching the critical level after exposure to $\mathrm{Cd}$ at nonacute toxic doses [5-9]. Therefore, MT can restrain effectively the toxicity of $\mathrm{Cd}$ in vivo.

However, the physiological environment is a very complex system. Under certain conditions, $\mathrm{Cd}^{2+}$ can be released from its bond with MT in some tissues such as liver, in which toxicity may appear again [10]. As well known, nanomaterials and nanotechnology are developing rapidly in recent years and are paid close attention to in medicine, pharmacy, genetic engineering, and so on, and also there are a lot of researches on the environmental toxicity about them [11-14]. Through oral, intraperitoneal, intravenous, and intragastric exposure ways, researchers study fully the biodistribution, excretion, and toxicity of carbon nanotubes in vivo by using isotope tracer technique or fluorescence imaging and find that carbon nanotubes are mainly in the liver, spleen, and lung tissues with a long retention [15-20]; at the same time, due to the unique scale effect and large specific surface area, carbon nanotubes show strong adsorption capacities for metal ions 
in water system [21]. Therefore, $\mathrm{Cd}^{2+}$ should be easy into the living things with nanomaterials in real environment, and that may aggravate toxicity of single carbon nanotubes or $\mathrm{Cd}^{2+}$; meanwhile nanomaterials may change the toxicity and metabolic behavior of heavy metal ions in vivo; thereby, it was important for human health to study the cotoxicity of carbon nanotubes and heavy metal ions in the organism.

In the present work, the effects of oxidation multiwalled carbon nanotubes (oMWCNTs) on the behavior and hepatotoxicity of cadmium (Cd) were investigated. Because the hormone levels (such as ALT, AST, BUN, and TB) in blood would change when there was some damage in liver or kidney tissues [22-24], the levels of ALT, AST, BUN, and $\mathrm{TB}$ in serum/or plasma were also measured to determine the toxicity of $\mathrm{Cd}^{2+}$ or oMWCNTs in livers or kidneys.

\section{Materials and Methods}

2.1. Preparation of Oxidized MWCNTs. Multiwalled carbon nanotubes (MWCNTs) were purchased from Shenzhen Nanotech Port Co. Ltd., Guangdong, China, and prepared using chemical vaporization deposition method. According to the product specification, as-received MWCNTs were determined with transmission electron microscopy (TEM) to be 1 to $2 \mu \mathrm{m}$ in length, with a diameter of 10 to $30 \mathrm{~nm}$. Purity was $>96 \%$ (wt. \%), containing $<3 \%$ amorphous carbon and $<0.2 \%$ ash. The as-grown MWCNTs (named as untreated MWCNTs) were added into the solution of $3 \mathrm{~mol} / \mathrm{L} \mathrm{HNO}_{3}$ to remove the metal hemispherical caps on the nanotubes (such as $\mathrm{Fe}, \mathrm{Ni}$ ) that was a byproduct of the synthetic procedure. The mixture of $3 \mathrm{~g}$ MWCNTs and 400-mL $3 \mathrm{~mol} / \mathrm{L}$ $\mathrm{HNO}_{3}$ was ultrasonically stirred for $24 \mathrm{~h}$. The suspension was filtrated and rinsed with deionized water until the $\mathrm{pH}$ of the suspension reached about 6 and then dried at $80^{\circ} \mathrm{C}$. The treated MWCNTs (named oMWCNTs) were calcined at $450^{\circ} \mathrm{C}$ for $24 \mathrm{~h}$ to remove the amorphous carbon [25]. And then oMWCNTs were made FT-IRs and Raman spectroscopy characterization; the results are shown in Figures 1 and 2, respectively. Other chemical reagents, such as $\mathrm{HNO}_{3}$, alcohol, and chloroform (ultrapure grade), were purchased from Tianjin Fuyu Chemical Co., Ltd., China; TRIS (ultrapure grade), from Sigma; Sephadex G-75 medium, from Pharmacia 17-0050-02; AST/ALT/BUN/TB (ELISA), from Shanghai Hengdailao Trade Co., Ltd., China.

2.2. Animals and Animal Model. Kunming mice (female: male $=1: 1$ ) initially weighing 15 to $18 \mathrm{~g}$ were provided by Laboratory Center for Medical Science, Lanzhou University, Gansu, China. All animals were housed in individual cages in a temperature $\left(21^{\circ} \mathrm{C}\right.$ to $22^{\circ} \mathrm{C}$ ) and light (from 08:00 to 20:00 hours) controlled environment and were fed food and tap water ad libitum. All animal protocols were in accordance with the European Communities Council Directive of November 24, 1986 (86/609/EEC), and approved by Institutional Animal Care and Use Committees of Gansu Province Medical Animal Center and Lanzhou University Animal Committees Guideline. Mice were pretreated with $\mathrm{CdCl}_{2}$ ( $1 \mathrm{mg} \mathrm{Cd} / \mathrm{kg}$ once daily subcutaneously for 6 days) to

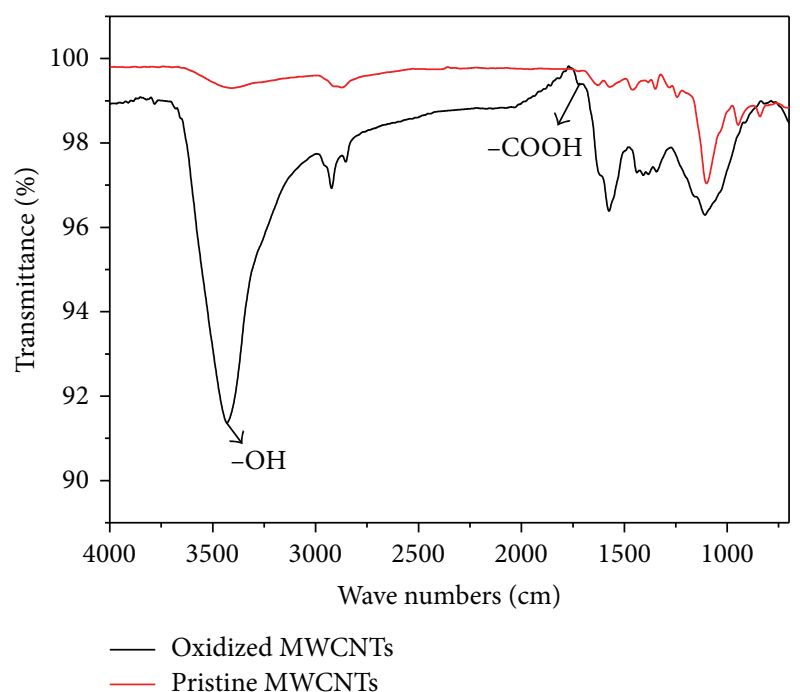

FIGURE 1: The FT-IRs of oxidized MWCNTs and pristine MWCNTs. The absorption peak of $3400 / \mathrm{cm}$ was $\mathrm{OH}-$ and that of $1720-1730 / \mathrm{cm}$ was $\mathrm{COOH}-$.

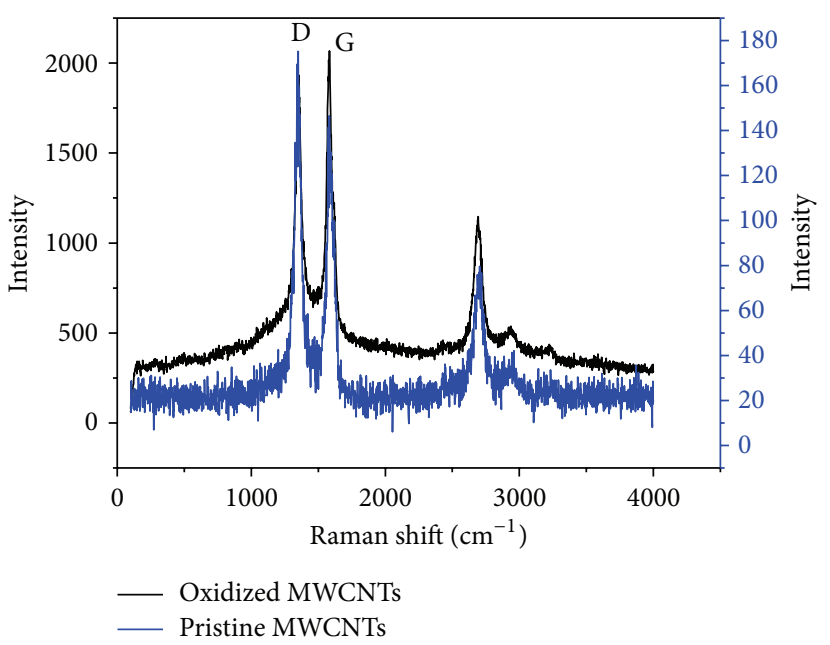

Figure 2: The Raman spectroscopy of oMWCNTs. The D and G band of MWCNT still existed after oxidation, indicating that carbon nanotube structure was not changed.

accumulate Cd-MT and those mice were referred to as CdMT accumulated mice.

2.3. The Effects of oMWCNTs on Inducing of Cd-MT. The livers were harvested at $4 \mathrm{~h}$ after intravenous exposure of oMWCNTs (about $500 \mu \mathrm{g} /$ mouse) to Cd-MT model (4 mice) and normal mice (4 mice), respectively. And the content changes curve of $\mathrm{Cd}-\mathrm{MT}$ and $\mathrm{Cd}^{2+}$ in liver was measured, according to the following steps to extract Cd-MT [26]. $4 \mathrm{~g}$ of liver tissue was cut into pieces, which were then put into $5 \mathrm{~mL}$ of precooling mixed liquid (Volume (Tris$\mathrm{HCl}, \mathrm{pH} 8.2)$ : Volume $\left(\mathrm{CH}_{3} \mathrm{CH}_{2} \mathrm{OH}\right)$ : Volume $\left(\mathrm{CH}_{3} \mathrm{Cl}\right)=$ $1: 1.03: 0.08)$, homogenate. After adding $20 \mathrm{~mL}$ of the mixed liquid into the liver homogenate and mixing them, the liver 


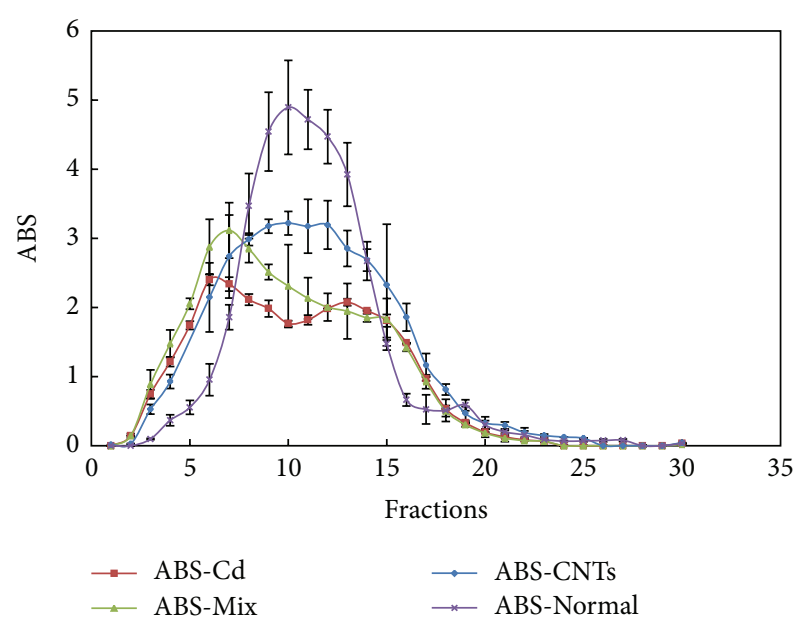

FIGURE 3: The eluent curves of processing liquid from liver tissues homogenate (ABS is the abbreviation of absorbance, absorption wavelength is $255 \mathrm{~nm}$ for ABS-Cd and ABS-Mix, and $260 \mathrm{~nm}$ for ABS-CNTs and ABS-Normal; $n=4$ mice).

homogenate was centrifuged for $20 \mathrm{~min}$ at $4000 \times \mathrm{g}$ in $4^{\circ} \mathrm{C}$; the supernatant was heated at $80^{\circ} \mathrm{C}$ for $5 \mathrm{~min}$, after cooling in cold water, and centrifuged for $20 \mathrm{~min}$ at $4000 \times \mathrm{g}$ in $4^{\circ} \mathrm{C}$; and the supernatant was diluted to 4 times volume with $-20^{\circ} \mathrm{C}$ precooled ethanol, stayed overnight at $-20^{\circ} \mathrm{C}$, and then centrifuged for $30 \mathrm{~min}$ at $4000 \times \mathrm{g}$ in $4^{\circ} \mathrm{C}$; the precipitation was dissolved fully in $0.01 \mathrm{~mol} / \mathrm{L}$ Tris- $\mathrm{HCl}$ buffer solution and then centrifuged for $20 \mathrm{~min}$ at $4000 \times \mathrm{g}$ in $4^{\circ} \mathrm{C}$. The supernatant was applied to a Sephadex G-75 column $(2 \mathrm{~cm}$ $\times 80 \mathrm{~cm})$ equilibrated with $0.01 \mathrm{~mol} / \mathrm{L}$ Tris- $\mathrm{HCl}(\mathrm{pH} 8.2)$; the column was eluted with the same buffer solution, and $4 \mathrm{~mL}$ fractions were collected to measure the absorbance by Ultraviolet Absorption Spectrophotometry (Lambda 35, PerkinElmer) and the Cd content of fractions was determined through Atomic Absorption Spectrophotometry (A Analyst 700, PerkinElmer).

2.4. The Effect of oMWCNTs on Hepatotoxicity of Cd. Three groups of Cd-MT model mice and normal mice $(6$ mice/ group) were exposed to oMWCNTs about $100 \mu \mathrm{g} / \mathrm{mouse}$, $500 \mu \mathrm{g} /$ mouse, and $750 \mu \mathrm{g} /$ mouse, respectively. After $4 \mathrm{~h}$ or $24 \mathrm{~h}$, the blood $(1 \mathrm{~mL})$, liver, and kidney were harvested and the blood with anticoagulant was used to measure the activities of alanine aminotransferase (ALT), aspartate aminotransferase (AST), total bilirubin (TB), and blood urea nitrogen (BUN) by ELISA testing. The liver, kidney, and blood were digested with the mixture of perchloric acid and $30 \%$ of hydrogen peroxide ( $3: 1$, volume) [27], and then the content of Cd was determined through Atomic Absorption Spectrophotometry. At the same time, the kidney and liver of all groups were obtained and fixed in 10\% buffered formalin and processed for routine histology with hematoxylin and eosin stain by the Center for Medical Science, Lanzhou University (Lanzhou, China). Microscopic observation of tissues was carried out with an Olympus Microphot-CX41 microscope coupled with a digital camera.
2.5. Statistical Analysis. Data were analyzed for significance using Student's $t$-test and a two-tailed analysis of variance (ANOVA). Differences were considered significant at $P<$ 0.05 .

\section{Results}

3.1. FT-IRs and Raman Spectrum of oMWCNTs. From Figure 1 it could be seen that the surface of carbon nanotubes was combined with a number of $-\mathrm{COOH}$ and $-\mathrm{OH}$ after oxidization; Figure 2 indicated that the structure of carbon nanotubes was not changed after oxidation.

3.2. The Effects of oMWCNTs on Inducing Cd-MT. It was reported that the UV adsorption peak of Cd-MT was about $250 \mathrm{~nm}$ [28], the maximum absorption was $255 \mathrm{~nm}$ for eluent of accumulated Cd-MT mice liver in this work, and two peaks in the curve of ABS-fractions could be observed, which was similar to the results of exposure group to oMWCNTs (Figure 3), but the second peak was lower than the first elution peak and the detailed reasons would be discussed in the following section.

However, the maximum absorption in elution was $260 \mathrm{~nm}$ for normal and single exposure groups (Figure 3) and there was only one peak in ABS-fractions curve. The changes of Cd content in elution of Cd-MT model and coexposure groups were consistent with Cd-MT elution curve (Figure 4). The results indicated that $\mathrm{Cd}$ could induce MT synthesis and accumulate in liver in the form of Cd-MT, but single oMWCNTs exposure could not induce MT synthesis. In addition, after exposure of oMWCNTs to Cd-MT model mice, oMWCNTs could affect the synthesis of Cd-MT.

3.3. The Effects of oMWCNTs on Cd Hepatotoxicity. The results of Figure 5 showed the distribution of $\mathrm{Cd}$ content in liver, kidney, and blood after exposure of different doses of oMWCNTs to Cd-MT model mice. Compared with the CdMT model group, the Cd contents were significantly lower in liver, kidney, and blood of exposure groups (Figure 5(a), $\left.{ }^{*} P<0.05\right)$, indicating that oMWCNTs could release Cd from Cd-MT in tissues; the Cd content of exposure group to $100 \mu \mathrm{g} /$ mouse oMWCNTs was less than that of 500 and $750 \mu \mathrm{g} /$ mouse for liver tissue, but higher than that for kidney and blood, which showed that the low-dosage of oMWCNTs had a stronger influence on Cd-MT in vivo. Because free Cd was absorbed onto oMWCNTs and agglomerated in organism together with oMWCNTs, the influence of exposure group to $750 \mu \mathrm{g} /$ mouse oMWCNTs was obviously higher than that to $500 \mu \mathrm{g} / \mathrm{mouse}$.

The ALT content in blood plasma decreased after exposing different doses of oMWCNTs to Cd-MT model mice (Figure 6(a)), but the decreased tendency was weakening with the increasing of oMWCNTs dose. For the exposure group with $750 \mu \mathrm{g} / \mathrm{mouse}$ oMWCNTs, the ALT content showed no difference with the Cd-MT model group. Compared to the single oMWCNTs exposure group, the ALT content of the coexposure group was significantly lower (Figure 6(a)). For the $750 \mu \mathrm{g} /$ mouse exposure groups, the 


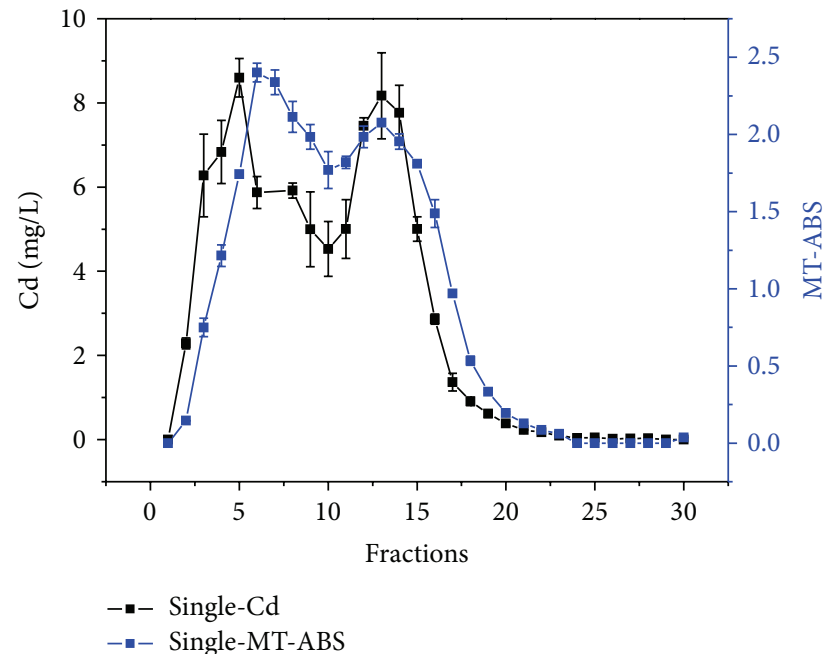

(a)

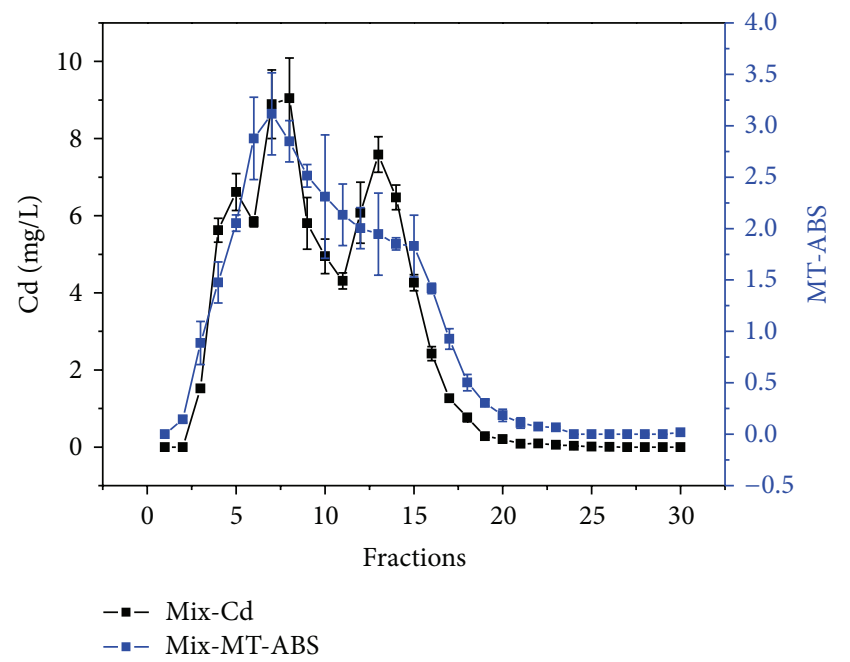

(b)

FIGURE 4: The changing curves of Cd concentration in Cd-MT are consistent with the absorption curves of MT (ABS is the abbreviation of absorbance; (a) is for Cd-MT model mice group; (b) is for coexposure mice group; $n=4$ mice).

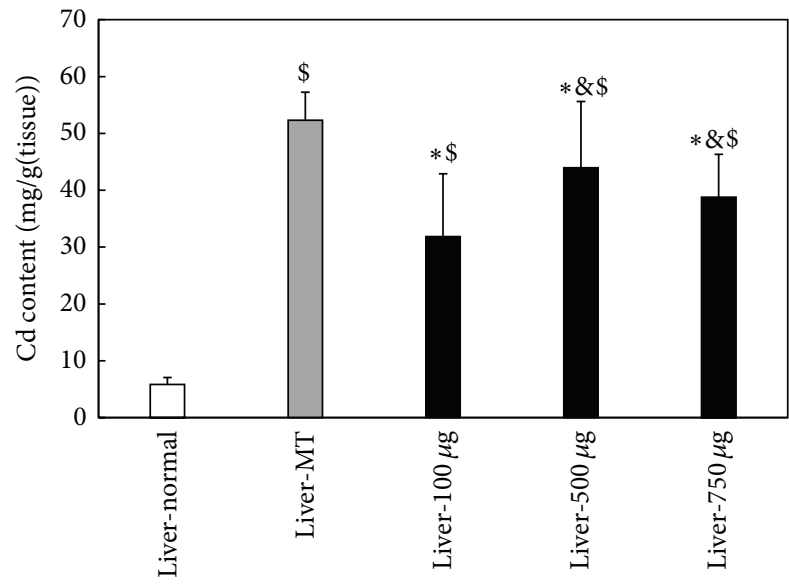

(a)

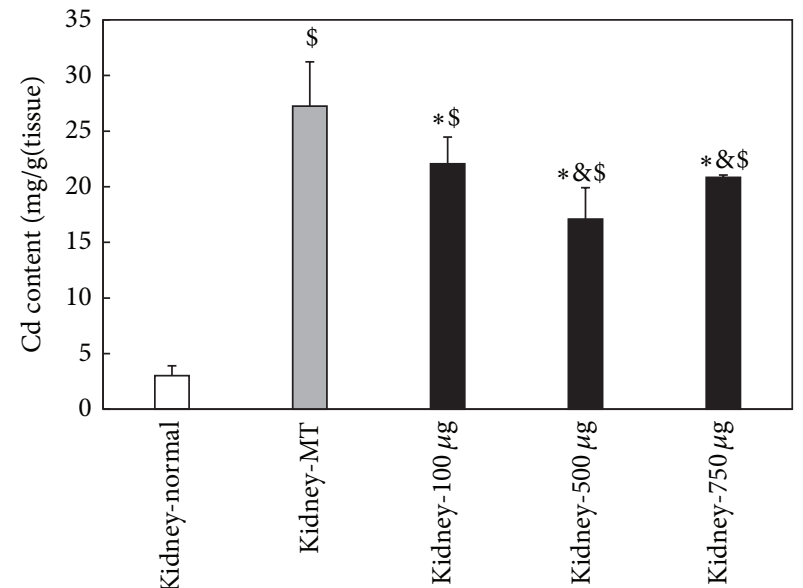

(b)

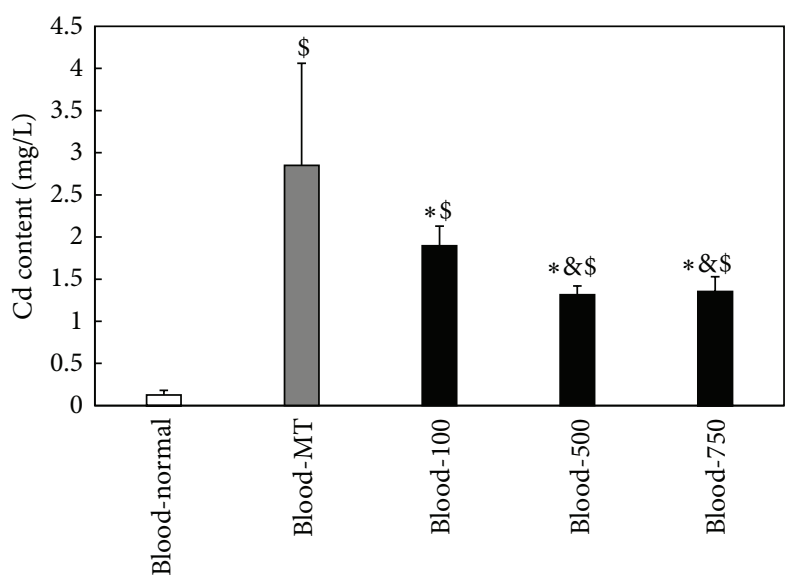

(c)

Figure 5: Release of $\mathrm{Cd}^{2+}$ from Cd-MT after exposure of different dosages of oMWCNTs to Cd-MT model mice. ((a) For Cd from liver, (b) for Cd from kidney, and (c) for Cd from blood; ${ }^{*} P<0.05$, groups versus MT group; ${ }^{\$} P<0.05$, groups versus normal group; ${ }^{\circledR} P<0.05$, groups versus $\mathrm{K}-100 \mu \mathrm{g} . n=6$ mice). 


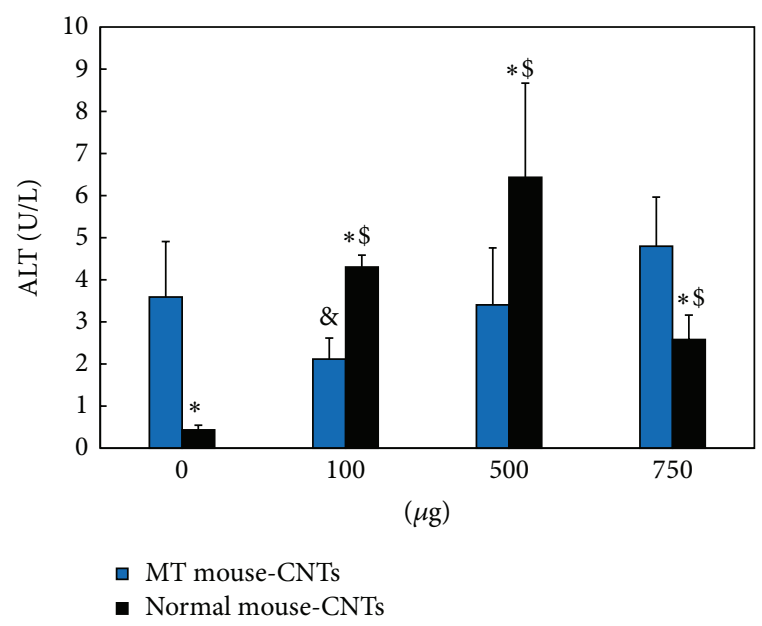

(a)

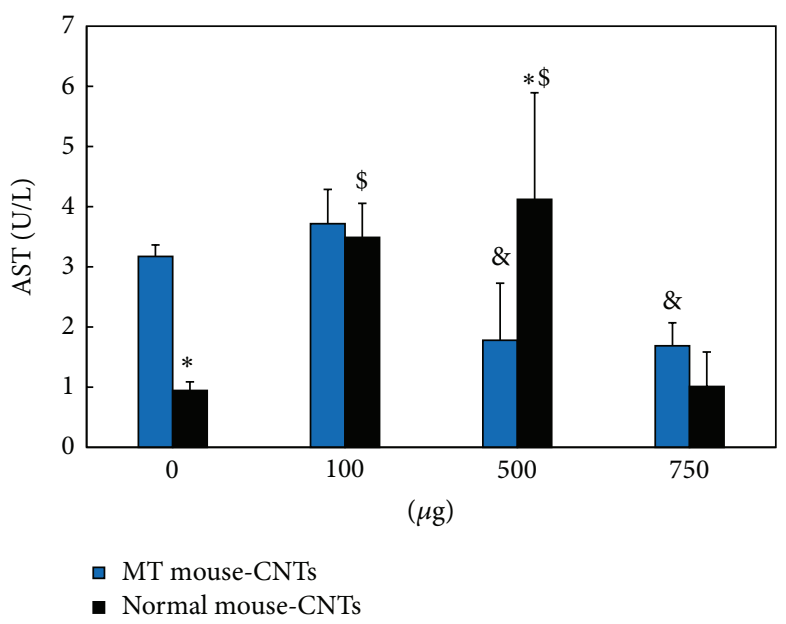

(b)

FiguRE 6: The effects of oMWCNTs on Cd hepatotoxicity and renal toxicity. ((a) For the changing of alanine aminotransferase (ALT) and (b) for the changing of aspartate aminotransferase (AST); ${ }^{*} P<0.05$ for Normal-CNTs versus MT-CNTs at the same CNTs dose; ${ }^{\&} P<0.05$ for groups versus MT-0 $\mu \mathrm{g}$ CNTs group; ${ }^{\$} P<0.05$ for groups versus Normal- $0 \mu \mathrm{g}$ CNTs Groups; $n=6$ mice).

ALT levels of single exposure group were lower than that of coexposure group. As shown in Figure 6(b), when the exposure concentration reached $500 \mu \mathrm{g} /$ mouse or $750 \mu \mathrm{g} /$ mouse for Cd-MT model mice, the AST levels in blood plasma began to decrease. However, compared with the single exposure groups, the AST content of the coexposure groups showed no significant difference, indicating that the impact of oMWCNTs on the secretion of AST was poor for CdMT model mice. As the histology of kidney and liver of all groups shown (Figure 7), compared with the control group, the histology indicated that the kidney tissue of MT group and the liver tissue of single oMWCNTs exposure group were minimal lesion disease, but the kidney of coexposure group showed serious pathological changes, including tissue edema, bleeding, and the karyotheca dissolved. And the further investigation also showed that the TB content of coexposure group to $100 \mu \mathrm{g} / \mathrm{mice}$ or $500 \mu \mathrm{g} / \mathrm{mice}$ oMWCNTs was lower than that of single exposure to $\mathrm{Cd}$ or oMWCNTs (Figure 8(a)); and after single exposure to normal mice with different oMWCNTs doses, the BUN content in plasma would be less than that in MT mice, which might reflect the disorder of kidney, but the BUN level was almost close to normal level (Figure 8(b)). And those results were according to the result of histology.

\section{Discussion}

The present work studied preliminarily the behavior and hepatotoxicity of heavy metal ions $\left(\mathrm{Cd}^{2+}\right)$ in presence of oMWCNTs in mice. It was proposed that the maximum absorption peak appeared around $250 \mathrm{~nm}$ for Cd-MT [28] and the results of the experiment illustrated that oMWCNTs could not induce the liver of mice synthesis MT, and $\mathrm{Cd}^{2+}$ induced successfully Cd-MT synthesis in liver tissue in mice (Figures 3 and 4). Yanjiao et al. reported that MT folded into two separate domains ( $\alpha$ and $\beta$ ) exhibiting different structures and functions independently, and Cd preferred to bind with $\alpha$ domains compared to $\beta$ domains. In addition, the absorption peak for $\beta$ domains at $254 \mathrm{~nm}$ was less significant than that for $\alpha$ domains [29]. This may be the reasons that the elution curve shows two different strength peaks for the Cd-MT model and coexposure groups (Figure 4(b)).

Our previous works indicated that oMWCNTs accumulated mainly in liver, lung, spleen, and kidney in mice after injection intravenously [15]; and $\mathrm{Cd}^{2+}$ accumulated in liver and kidney in the form of Cd-MT in vivo [10]. The authors chose the changes of $\mathrm{Cd}^{2+}$ content in blood, liver, and kidney to investigate the influence of oMWCNTs on Cd-MT in mice. After oMWCNTs exposure to Cd-MT model mice, oMWCNTs interacted with the accumulated $\mathrm{Cd}-\mathrm{MT}$ in liver and kidney and then released $\mathrm{Cd}^{2+}$ from Cd-MT into blood circulatory system (Figure 5). Most of free $\mathrm{Cd}^{2+}$ would be eliminated through circulatory system, leading to the decrease of $\mathrm{Cd}^{2+}$ in blood, liver, and kidney and increase of toxicity of $\mathrm{Cd}^{2+}$ in kidney, which could be seen from the histology of the kidney and liver tissue (Figure 7) and the level of BUN and TB; but another part of $\mathrm{Cd}^{2+}$ adsorbed onto oMWCNTs continued to accumulate in tissues together with oMWCNTs. Because the content of oMWCNTs in liver increased with the increase of injection dosage of oMWCNTs, more free $\mathrm{Cd}^{2+}$ ions retained together with oMWCNTs in the liver, resulting in the decrease of $\mathrm{Cd}^{2+}$ content in the kidney (Figure 5). However, when the CdMT model mice were exposed to $750 \mu \mathrm{g} /$ mouse oMWCNTs, oMWCNTs were intercepted in lungs for the aggregation of high concentrations of oMWCNTs [30], and less oMWCNTs entered into liver and kidney; thus the effect on Cd-MT was reduced (Figure 5).

It was reported that oMWCNTs would be retained for long time in liver, lung, spleen, and other tissues after 

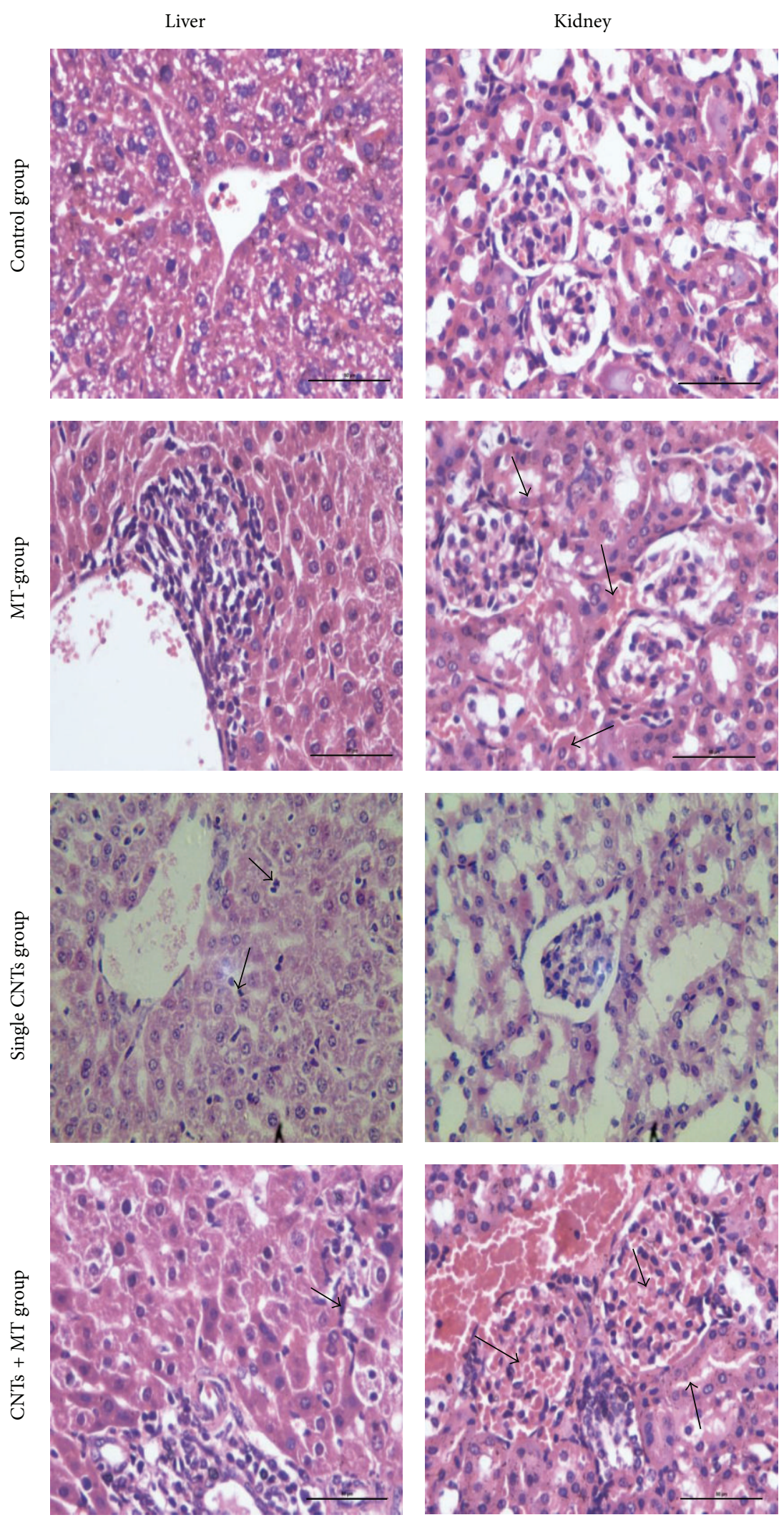

FIGURE 7: The histology of liver and kidney of control, MT, single CNTs exposure, and coexposure groups. (The arrows in the figure showed the pathological changes of tissue.) 


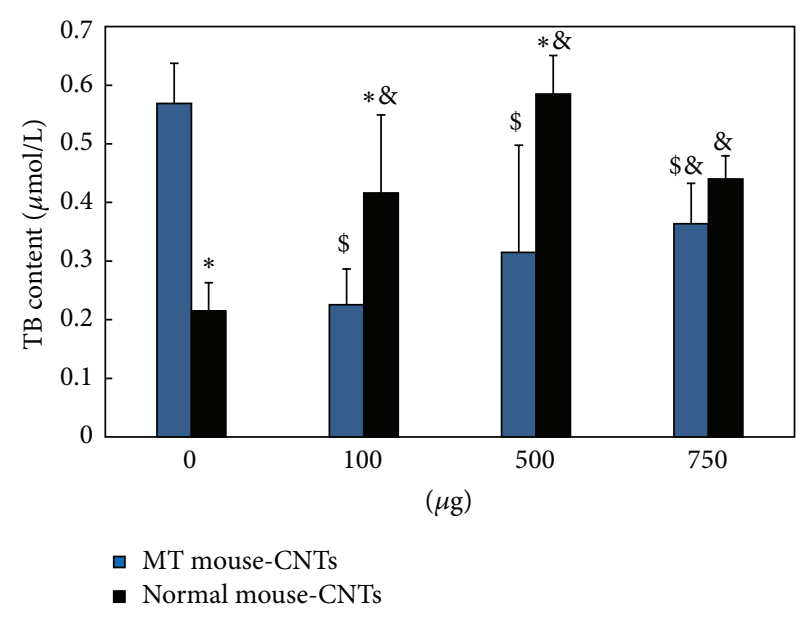

(a)

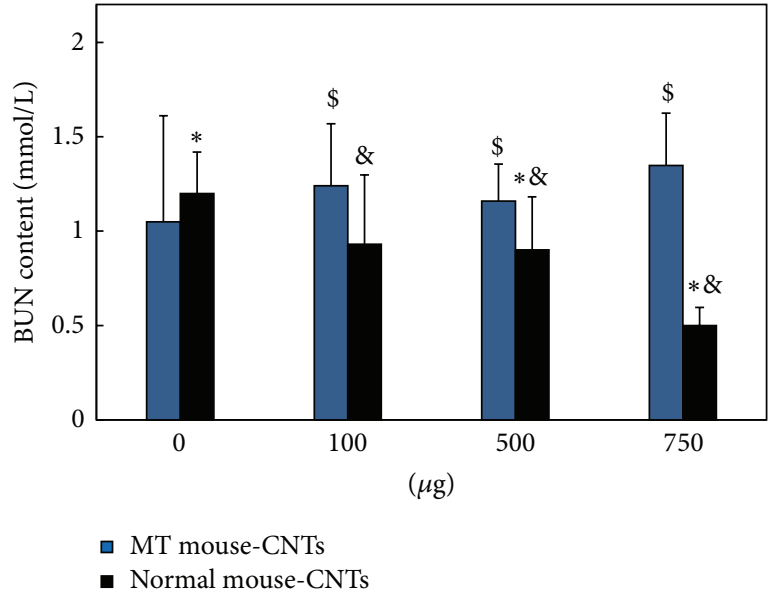

(b)

FIGURE 8: The effects of oMWCNTs on Cd renal toxicity. ((a) For the changing of total bilirubin (TB) and (b) for the changing of blood urea nitrogen (BUN); ${ }^{*} P<0.05$ for Normal-CNTs versus MT-CNTs at the same CNTs dose; ${ }^{\circledR} P<0.05$ for groups versus Normal- $0 \mu \mathrm{g}$ CNTs group; ${ }^{\$} P<0.05$ for groups versus MT-0 $\mu$ g CNTs groups; $n=6$ mice).

entering into body and damaged the tissues through inducing inflammation, granuloma, cell apoptosis and DNA damage, and so on $[18,20] . \mathrm{Cd}^{2+}$ stimulated the liver and kidney to produce MT after exposure and was accumulated in the form of Cd-MT in tissues. After oMWCNTs exposure to Cd-MT model mice, oMWCNTs could release $\mathrm{Cd}^{2+}$ from Cd-MT in liver into circulation system, and then $\mathrm{Cd}^{2+}$ was eliminated out from body to decrease its accumulation in liver. The $\mathrm{Cd}^{2+}$ hepatotoxicity was decreased for liver (Figures 5 and $6)$, but the released $\mathrm{Cd}^{2+}$ ions could enter into kidney and increase their damage to kidney (Figures 7 and 8). Some researchers also found that some proteins would combine with oMWCNTs in vivo, which could improve the biological compatibility and metabolic capacity of oMWCNTs and the biological toxicity of oMWCNTs was reduced [31]. Therefore, authors thought that MT as a kind of protein released from Cd-MT could bind with oMWCNTs to decrease the hepatotoxicity of oMWCNTs, leading to the fact that the content of ALT/AST/TB in plasma of Cd-MT model mice group was lower than that of single exposure to normal mice group with different oMWCNTs doses (Figures 6 and 8(a)). The detailed mechanism needs to be further investigated. Because the $\mathrm{Cd}^{2+}$ could be released from Cd-MT and the MT combined with oMWCNTs, the coexposure of $\mathrm{Cd}^{2+}$ and oMWCNTs to mice could decrease the hepatotoxicity significantly compared to single exposure. However, when the coexposure dosage of oMWCNTs was $750 \mu \mathrm{g} /$ mouse, most parts of oMWCNTs were retained in the lung tissue, which could reduce their damage to liver, and so their negative effects were less than those of low doses $(100 \mu \mathrm{g} / \mathrm{mice}$ or $500 \mu \mathrm{g} /$ mice) exposure groups.

\section{Conclusion}

The model mice with Cd-MT were made via injection with $\mathrm{Cd}^{2+}$ and then they were exposed to different dosages of
oMWCNTs. The results showed that oMWCNTs could cause $\mathrm{Cd}^{2+}$ releasing from the accumulated Cd-MT. After the oMWCNTs and $\mathrm{Cd}^{2+}$ were injected together or respectively, the content changes of ALT, AST, TB, and BUN in plasma and the histology of liver and kidney both indicated that the hepatotoxicity of coexposure was lower than that of single exposure. It can be deduced that MT could be connected with oMWCNTs to reduce their hepatotoxicity, but the detailed mechanisms needed further study.

\section{Conflict of Interests}

The authors declare that there is no conflict of interests regarding the publication of this paper.

\section{References}

[1] J. Chmielnicka and B. Sowa, "Cadmium interaction with essential metals ( $\mathrm{Zn}, \mathrm{Cu}, \mathrm{Fe}$ ), metabolism metallothionein, and ceruloplasmin in pregnant flats and fetuses," Ecotoxicology and Environmental Safety, vol. 35, no. 3, pp. 277-281, 1996.

[2] E. Casalino, C. Sblano, and C. Landriscina, "Enzyme activity alteration by cadmium administration to rats: the possibility of iron involvement in lipid peroxidation," Archives of Biochemistry and Biophysics, vol. 346, no. 2, pp. 171-179, 1997.

[3] D. Bagchi, S. S. Joshi, M. Bagchi et al., "Cadmium- and chromium-induced oxidative stress, DNA damage, and apoptotic cell death in cultured human chronic myelogenous leukemic K562 cells, promyelocytic leukemic HL-60 cells, and normal human peripheral blood mononuclear cells," Journal of Biochemical and Molecular Toxicology, vol. 14, no. 1, pp. 33-41, 2000.

[4] R. C. Patra, D. Swarup, and S. K. Senapat, "Effects of cadmium on lipid peroxides and superoxide dismutasein hepatic, renal and testicular tissue of rats," Veterinary and Human Toxicology, vol. 41, no. 2, pp. 65-67, 1999.

[5] J. Kägi and Y. Kojima, Chemistry and biochemistry of metallothionein, Metallothionein II, Springer, New York, NY, USA, 1987. 
[6] P. F. Searle, B. L. Davison, G. W. Stuart, T. M. Wilkie, G. Norstedt, and R. D. Palmiter, "Regulation, linkage, and sequence of mouse metallothionein I and II genes," Molecular and Cellular Biology, vol. 4, no. 7, pp. 1221-1230, 1984.

[7] K. Min, S. Onosaka, and K. Tanaka, "Renal accumulation of cadmium and nephropathy following long-term administration of cadmium-metallothionein," Toxicology and Applied Pharmacology, vol. 141, no. 1, pp. 102-109, 1996.

[8] Y. Liu, J. Liu, M. B. Iszard, G. K. Andrews, R. D. Palmiter, and C. D. Klaassen, "Transgenic mice that overexpress metallothionein-I are protected from cadmium lethality and hepatotoxicity," Toxicology and Applied Pharmacology, vol. 135, no. 2, pp. 222-228, 1995.

[9] Y. Suzuki, "Cadmium metabolism and toxicity in rats after longterm subcutaneous administration," Journal of Toxicology and Environmental Health, vol. 6, no. 3, pp. 469-482, 1980.

[10] K. Min, K. Shida, N. Tanaka, N. Yamashita, N. Tetsuchikawahara, and S. Onosaka, "Recurrence of toxicity by cadmium released from accumulated cadmium-metallothionein in mice," Journal of Health Science, vol. 51, no. 3, pp. 398-404, 2005.

[11] M. Chen, E. D. Pierstorff, R. Lam et al., "Nanodiamondmediated delivery of water-insoluble therapeutics," ACS Nano, vol. 3, no. 7, pp. 2016-2022, 2009.

[12] Z. Liu, S. Tabakman, K. Welsher, and H. Dai, "Carbon nanotubes in biology and medicine: in vitro and in vivo detection, imaging and drug delivery," Nano Research, vol. 2, no. 2, pp. 85120, 2009.

[13] Z. Liu, J. T. Robinson, X. M. Sun, and H. J. Dai, "PEGylated nanographene oxide for delivery of water-insoluble cancer drugs," Journal of the American Chemical Society, vol. 130, no. 33, pp. 10876-10877, 2008.

[14] K. A. Williams, P. T. M. Veenhuizen, B. G. De la Torre, R. Eritja, and C. Dekker, "Nanotechnology: carbon nanotubes with DNA recognition," Nature, vol. 420, no. 6917, p. 761, 2002.

[15] Z. Li, Y. X. Geng, X. Y. Zhang et al., "Biodistribution of coexposure to multi-walled carbon nanotubes and graphene oxide nanoplatelets radiotracers," Journal of Nanoparticle Research, vol. 13, no. 7, pp. 2939-2947, 2011.

[16] J. X. Guo, X. Zhang, Q. N. Li, and W. X. Li, "Biodistribution of functionalized multiwall carbon nanotubes in mice," Nuclear Medicine and Biology, vol. 34, no. 5, pp. 579-583, 2007.

[17] Z. Liu, C. Davis, W. Cai, L. He, X. Chen, and H. Dai, "Circulation and long-term fate of functionalized, biocompatible single-walled carbon nanotubes in mice probed by Raman spectroscopy," Proceedings of the National Academy of Sciences of the United States of America, vol. 105, no. 5, pp. 1410-1415, 2008.

[18] J. Muller, F. Huaux, N. Moreau et al., "Respiratory toxicity of multi-wall carbon nanotubes," Toxicology and Applied Pharmacology, vol. 207, no. 3, pp. 221-231, 2005.

[19] X. Y. Zhang, J. L. Yin, C. Kang et al., "Biodistribution and toxicity of nanodiamonds in mice after intratracheal instillation," Toxicology Letters, vol. 198, no. 2, pp. 237-243, 2010.

[20] S. Yang, X. Wang, G. Jia et al., "Long-term accumulation and low toxicity of single-walled carbon nanotubes in intravenously exposed mice," Toxicology Letters, vol. 181, no. 3, pp. 182-189, 2008.

[21] J. Li, S. Chen, G. Sheng, J. Hu, X. Tan, and X. Wang, "Effect of surfactants on $\mathrm{Pb}(\mathrm{II})$ adsorption from aqueous solutions using oxidized multiwall carbon nanotubes," Chemical Engineering Journal, vol. 166, no. 2, pp. 551-558, 2011.
[22] R. E. Dudley, D. J. Svoboda, and C. D. Klaassen, "Acute exposure to cadmium causes severe liver injury in rats," Toxicology and Applied Pharmacology, vol. 65, no. 2, pp. 302-313, 1982.

[23] R. A. Kohn, M. M. Dinneen, and E. Russek-Cohen, "Using blood urea nitrogen to predict nitrogen excretion and efficiency of nitrogen utilization in cattle, sheep, goats, horses, pigs, and rats," Journal of Animal Science, vol. 83, no. 4, pp. 879-889, 2005.

[24] T. S. Perlstein, R. L. Pande, J. A. Beckman, and M. A. Creager, "Serum total bilirubin level and prevalent lower-extremity peripheral arterial disease: National Health and Nutrition Examination Survey (NHANES) 1999 to 2004," Arteriosclerosis, Thrombosis, and Vascular Biology, vol. 28, no. 1, pp. 166-172, 2008.

[25] X. Wang, C. Chen, W. Hu, A. Ding, D. Xu, and X. Zhou, "Sorption of $243 \mathrm{Am}$ (III) to multiwall carbon nanotubes," Environmental Science and Technology, vol. 39, no. 8, pp. 2856-2860, 2005.

[26] M. Yu, Y. He, L. Zhou et al., "A simple method for preparing metallothionein," Journal of Isotopes, vol. 9, no. 1, 1996.

[27] X. W. Wang, J. Y. Gu, Z. Li, Y. F. Song, W. S. Wu, and Y. P. Hou, "Gestational age and dose influence on placental transfer of 63Ni in rats," Placenta, vol. 31, no. 4, pp. 305-311, 2010.

[28] L. Tío, L. Villarreal, S. Atrian, and M. Capdevila, "The Znand Cd-clusters of recombinant mammalian MT1 and MT4 metallothionein domains include sulfide ligands," Experimental Biology and Medicine, vol. 231, no. 9, pp. 1522-1527, 2006.

[29] Z. Yanjiao, Y. Xiong, L. Lingyuan, and R. Binggen, "Study on the structure and function of A and B domain of metallothionein," Chinese Journal of Biochemistry and Molecular Biology, vol. 15, 1999.

[30] W. Qi, Z. Li, J. Bi et al., "Biodistribution of co-exposure to multi-walled carbon nanotubes and nanodiamonds in mice," Nanoscale Research Letters, vol. 7, article 473, 2012.

[31] C. Salvador-Morales, P. Townsend, E. Flahaut et al., "Binding of pulmonary surfactant proteins to carbon nanotubes; potential for damage to lung immune defense mechanisms," Carbon, vol. 45, no. 3, pp. 607-617, 2007. 

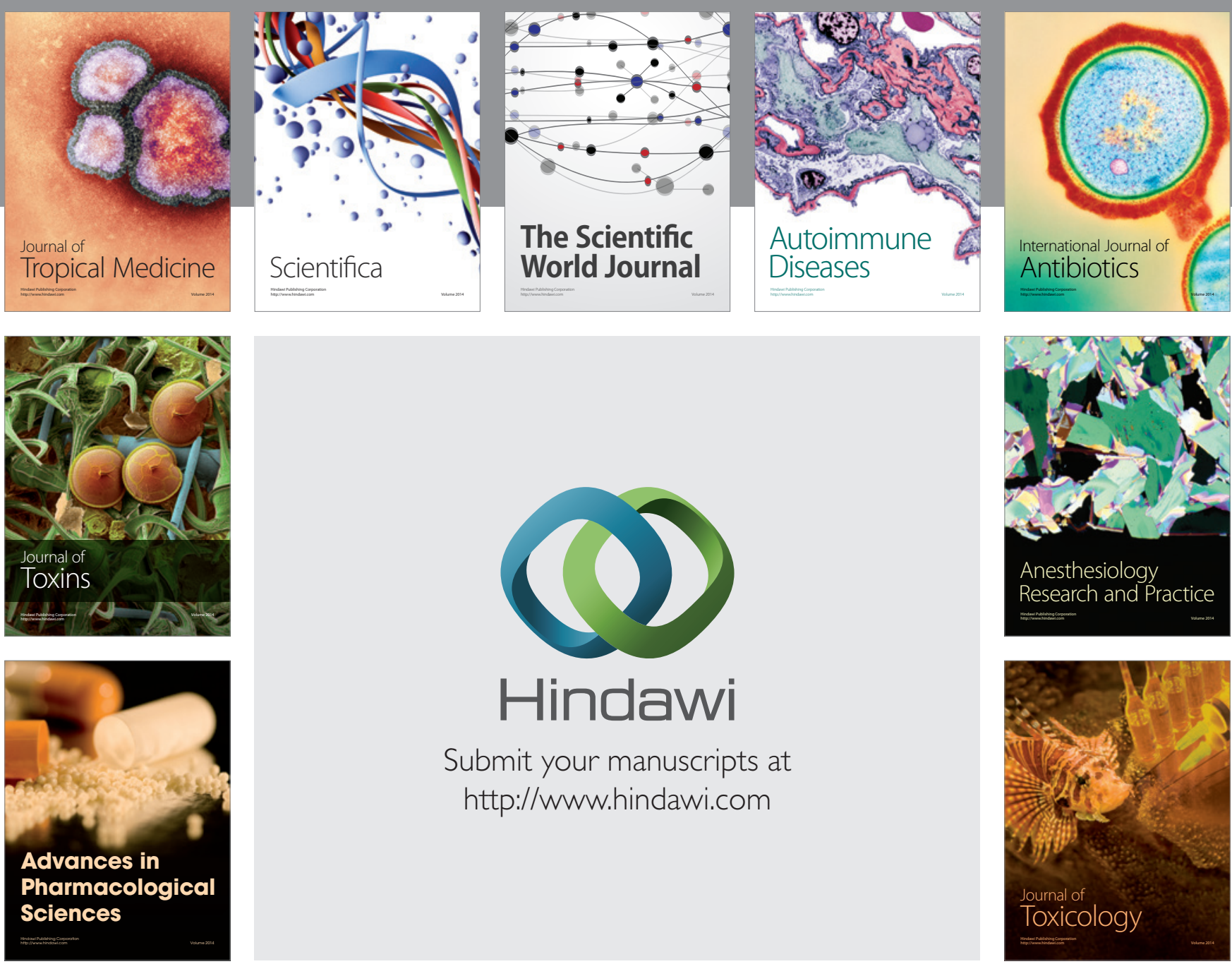

\section{Hindawi}

Submit your manuscripts at

http://www.hindawi.com
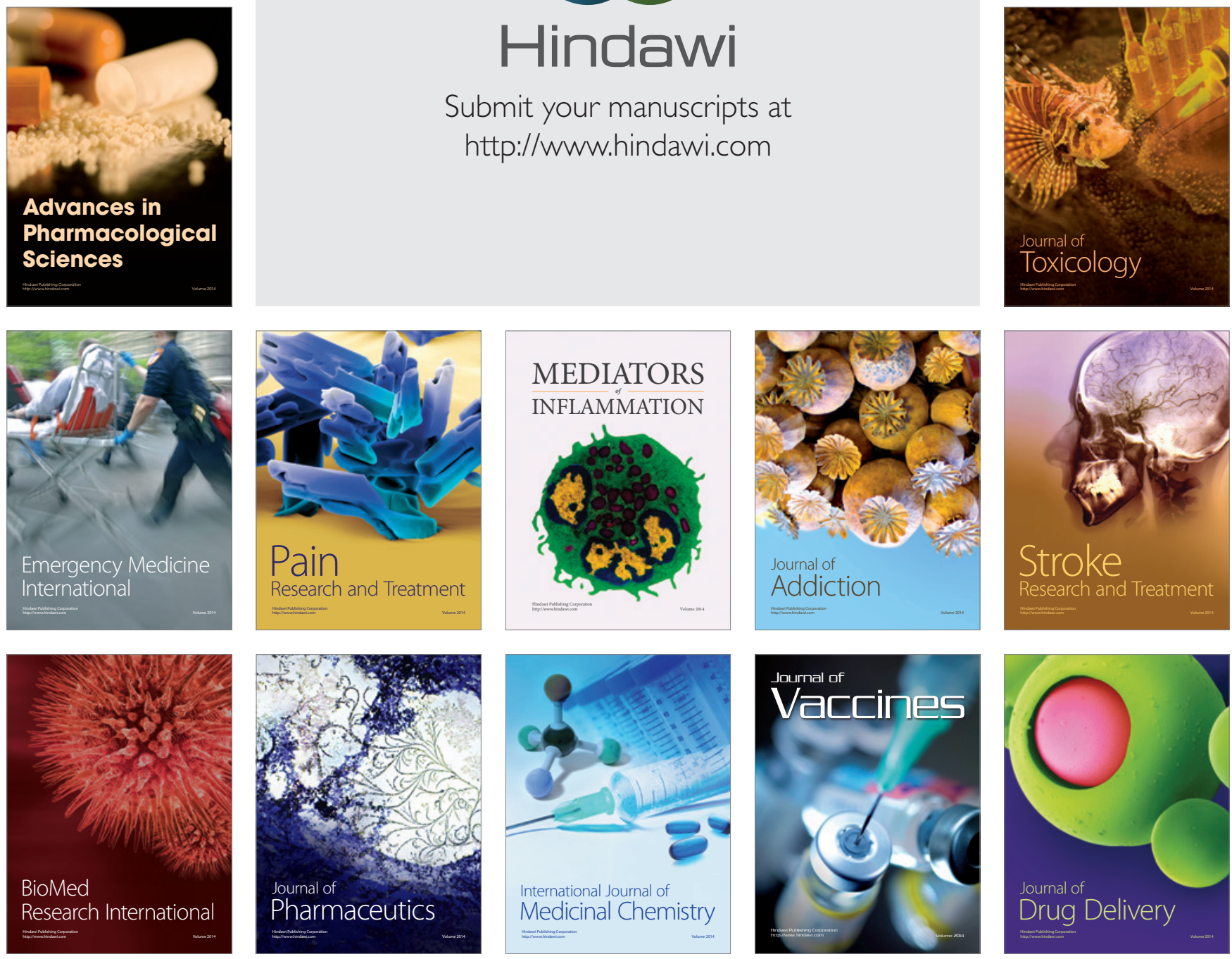